\title{
Ciência Aberta na América Latina: duas perspectivas em disputa
}

\author{
Open Science in Latin America: Two \\ perspectives in dispute
}

Anne CLINIO1 (iD) 0000-0002-9702-859X

\begin{abstract}
Resumo
O artigo pretende fomentar debates sobre o desenvolvimento da Ciência Aberta na América Latina. Para tanto, apresenta, na primeira seção, elementos para subsidiar uma análise de conjuntura sobre esse movimento internacional, buscando identificar, através de discursos e ações dos atores que estão conduzindo este debate, suas motivações e direções. Posteriormente, na segunda seção, serão apresentadas perspectivas latino-americanas a partir da experiência da rede de pesquisa Open and Collaborative Science in Development Network e de debates para elaboração da Declaração do Panamá sobre Ciência Aberta por ativistas e pesquisadores em novembro de 2018. As considerações finais indicam a existência de, pelo menos, duas perspectivas em disputa: a primeira fomenta uma visão utilitarista da ciência em termos de maior eficácia, produtividade e competitividade; a segunda se volta para temas como garantia de direitos, justiça cognitiva e justiça social. Esse debate dialoga estreitamente com o fenômeno do capitalismo acadêmico e com a transição das universidades de seu papel de agente de mudança social, a partir da produção do conhecimento como bem comum para um empreendimento orientado ao mercado e à ideia de eficiência.
\end{abstract}

Palavras-chave: América Latina. Análise de conjuntura. Ciência Aberta.

\begin{abstract}
The article aims to foster consistent debates about Open Science development in Latin America. Thus, it presents, in the first section, elements to support a conjuncture analysis about this international movement, seeking to identify through discourses and actions of the agents who are conducting this debate, their motivations and directions. Subsequently, in the second section, this study presents Latin American perspectives from the experience of the Open and Collaborative Science Research Network in Development Network and the discussions on the elaboration of the Panama Declaration on Open Science by activists and researchers in November 2018. In the concluding remarks, indicates the existence of, at least, two Open Science perspectives in dispute. The first fosters a utilitarian view of science in terms of greater effectiveness, productivity and competitiveness while the second ones focuses on issues such as the guarantee of rights, cognitive justice and social justice. This debate dialogues closely with the phenomenon of academic capitalism and the transition of universities from knowledge production institutions for the common good to a market-oriented enterprise and the idea of efficiency.
\end{abstract}

Keywords: Latin America. Conjuncture analysis. Open Science.

1 Fundação Oswaldo Cruz, Vice Presidência de Ensino, Informação e Comunicação. Av. Brasil, 4365, Castelo Mourisco, Sala 112, Manguinhos, 21040-900, Rio de Janeiro, RJ, Brasil. E-mails: <anne.santos@fiocruz.br>; <anne@clinio.net>.

Recebido em 8 de março de 2019, reapresentado em 3 de outubro de 2019 e aprovado em 22 de outubro de 2019.

Como citar este artigo/How to cite this article

Clinio, A.Ciência aberta na América Latina: duas perspectivas em disputa. Transinformação, v.31, e190028. http://dx.doi.org/10.1590/238180889201 $931 e 190028$ 


\section{Introdução}

Atualmente, diversos atores do sistema de Ciência,Tecnologia e Inovação parecem concordar com a proposta, quase imperativa, de "abertura" da ciência. Essa insólita coincidência não indica apenas o alto grau de ambiguidade dessa expressão, mas camufla distintos significados, pressupostos e interesses na adoção do paradigma aberto como "novo" orientador da ciência. Em geral, os evangelistas da Ciência Aberta apresentam como prognóstico inquestionável que a abertura promoverá o aumento da qualidade, da quantidade e da velocidade de informação circulante que, por sua vez, acarretará no avanço mais rápido e mais eficiente da ciência, tanto em termos de produção de conhecimento, como no desenvolvimento de soluções para os problemas que afligem a humanidade.

É mobilizada uma miríade de argumentos, como promover a eficiência do processo científico, democratizar o acesso ao conhecimento científico, promover a transparência, estimular a inovação, maximizar os estoques de conhecimento confiável, envolver a sociedade em processos de cocriação de conhecimento etc. No entanto, o inconveniente desse tipo de raciocínio é que ele cria uma falsa relação de causa e efeito para justificar os supostos benefícios de "abrir", em uma direção imprecisa e pretensamente autorregenerativa e autoequilibrada, as formas de se fazer ciência. De modo mais claro, essa explicação exclui do debate o processo histórico amplo, intrincado e contingente das transformações já em curso.

O economista Paul David pesquisou o alvorecer do que ele identifica como um primeiro momento de Ciência Aberta, notadamente a própria Revolução Científica, a partir do estudo dos incentivos para que os atores sociais adotassem a nova perspectiva (David, 2008). O autor recusa explicações funcionalistas que enfatizam a convergência do incentivo de comportamentos cooperativos com propriedades de maior eficiência econômica e social. Ademais, reconhece que diversos fatores influenciam, em menor ou maior grau, a emergência de uma Ciência Aberta na Europa aristocrática e pré-capitalista no final do século XVI e começo do século XVII, a despeito de diversas condições adversas como, por exemplo, o monopólio da autoridade pelas instituições religiosas.

No entanto, segundo David, a especificidade da Revolução Científica reside no seu aspecto organizacional na medida que enfraquece o ethos até então dominante, baseado no sigilo, e elabora um novo conjunto de instituições, normas, incentivos e estruturas que promovem a rápida divulgação de novos conhecimentos. Tem-se como exemplo o enfraquecimento de tradições secretistas, como os pequenos círculos de alquimistas que não revelam publicamente suas descobertas, geralmente registradas em textos herméticos para proteger os "segredos divinos". Outro exemplo é a emergência de uma nova forma de organização, baseada nas práticas abertas da metalurgia, que promoviam, em alguma medida, a divulgação pública do conhecimento novo.

Em seu estudo, David (2008) também refuta a tese de Fontenelle de que a abertura promovida na Revolução Científica foi impulsionada por questões epistemológicas, intrínsecas aos novos métodos de pesquisa baseados em laboratórios e observatórios astronômicos - um argumento que pode ser análogo ao momento presente, com o big data. No seu entendimento, a formação de estruturas abertas e do ethos da Ciência Moderna (comunalismo, universalismo, desinteresse, originalidade e ceticismo organizado) são frutos da reorganização da "economia do patrocínio" a partir do enfrentamento de um problema prático: a assimetria de informação originada pela crescente matematização de vários campos de conhecimento e contextos de aplicação. Em outras palavras, é a necessidade dos nobres patronos, os financiadores, de entenderem as propostas daqueles que recebiam seu financiamento que gera os incentivos necessários para o estabelecimento de uma nova estrutura organizacional a qual enfatiza a divulgação pública de conhecimentos.

Além da singularidade de afirmar que o movimento por uma Ciência Aberta não é um fenômeno inédito, David (2008) também inova ao identificar que a Ciência Moderna opera a partir da coexistência de dois regimes organizacionais distintos, com diferentes propósitos, porém complementares. São eles a Ciência Aberta, e sua proposta de disseminação liberal da informação, e a Pesquisa e Desenvolvimento com orientação comercial, que se 
baseia em informações proprietárias. Os dois subsistemas são históricos, complementares e, quando alcançam um ponto de equilíbrio, seriam altamente produtivos na manutenção de um fluxo contínuo de conhecimento novo e na maximização de rendas econômicas pela exploração comercial de processos e produtos disponibilizados no mercado a partir de regras proprietárias.

Inspirado na recusa de David de uma explicação funcionalista, o presente artigo identifica atores, discursos e argumentos a favor da adoção da Ciência Aberta na América Latina com o objetivo de realizar uma "leitura especial da realidade" (Souza, 1984) e subsidiar análises de conjuntura sobre esse movimento. Dada a crescente tendência à institucionalização da Ciência Aberta, é necessário ser propositivo frente ao cenário internacional, reconhecendo tanto as especificidades e demandas regionais, como o seu imbricamento no sistema global de pesquisa e, por que não, de mercado. Em última instância, uma visão panorâmica do momento atual pode ajudar na elaboração de estratégias de intervenção - por formuladores de políticas e pelas diversas forças sociais interessadas na Ciência Aberta e em suas repercussões regionais.

Uma preocupação premente é a forte tendência ao open washing ("lavagem a aberto"em português), termo cunhado por Waters (2014) para assinalar a capacidade das corporações em adotar rapidamente sua linguagem e suas imagens para parecerem amigáveis, progressistas e inovadoras sem que haja alterações estruturais relevantes e positivas na direção da justiça social. Na mesma linha de pensamento, Mirowski (2018) faz duras críticas à Ciência Aberta, pois, além de vislumbrar a iminente frustração de "consertar o antigo regime da ciência", reconhece que o que está em jogo é a quebra do monopólio histórico da produção de conhecimento a partir de um estranho discurso "sem cheiro de mercado". Segundo o autor, o discurso hegemônico da Ciência Aberta associa o ethos de uma "ciência radicalmente colaborativa" às estruturas emergentes do "capitalismo de plataforma", representando um avanço neoliberal sobre o campo da produção do conhecimento científico.

Esse diagnóstico é corroborado pelas pesquisas de Pozada e Chen (2018) sobre as recentes aquisições de três das cinco principais editoras acadêmicas do mundo (Elsevier, Wiley, Taylor, and Francis), agora reposicionadas como "provedoras de soluções" ou "analistas de informação". Segundo os autores, essas empresas estão efetuando uma "integração vertical" de conteúdos e de infraestruturas para incorporar todo o fluxo de trabalho da pesquisa científica em produtos e serviços. Quem se beneficiaria de uma Ciência Aberta orientada pelas superestruturas do capitalismo global? Será ele o maior beneficiário da maximização da produtividade e da eficiência em pesquisa? Quem serão os excluídos? Quais são as repercussões?

O artigo está estruturado em três seções. Na primeira, são apresentados elementos que subsidiam uma análise de conjuntura através dos discursos e das ações dos seus principais atores, compilados a partir de pesquisa documental. Na segunda seção, é contrastada a perspectiva hegemônica com contribuições latino-americanas a partir da experiência da rede de pesquisa Open and Collaborative Science in Development Network (OCSDNet) e de debates em torno da elaboração da Declaração do Panamá sobre Ciência Aberta, por ativistas e pesquisadores em novembro de 2018 (Declaración..., 20--?). Por fim, serão feitas considerações sobre a disputa entre perspectivas.

\section{Elementos para uma análise de conjuntura: atores, motivações e discursos}

Conforme foi comentado, há uma clara convergência em torno da Ciência Aberta, mas, por detrás dessa ideia, ainda um tanto quanto abstrata, residem diversas expectativas e interesses. A Ciência Aberta é, em linhas gerais, um movimento que pretende tornar a pesquisa científica acessível para todos. Segundo a Open Knowledge International, por exemplo, "a Ciência Aberta significa muitas coisas, mas principalmente que o conhecimento

\footnotetext{
2 "Lavagem a aberto: substantivo. Ter a aparência de código aberto e licenciamento aberto para fins de marketing, enquanto mantém práticas proprietárias". No original: "Openwashing: n., having an appearance of open-source and open-licensing for marketing purposes, while continuing proprietary practices". - @audreywaters, March 26, 2012.
} 
científico deve ser livre para as pessoas usarem, reutilizarem e distribuírem sem restrições legais, tecnológicas ou sociais" (Open Knowaedge..., 20--?). Na prática, a abertura vem sendo promovida a partir de esforços para eliminar obstáculos artificiais à livre circulação do conhecimento, especialmente o científico, produzido em instituições formais de ensino e pesquisa.

Nesta seção, busca-se identificar atores, discursos e ações em prol da Ciência Aberta para assinalar tendências desse movimento. O "Livro Verde" (Santos, 2017) é um bom começo para explorar seus possíveis significados, pois sistematiza as estratégias de países protagonistas na crescente implantação de abertura de dados para pesquisa. Apesar de serem alheios ao continente, suas ações geram repercussões na América Latina, dado o financiamento internacional de pesquisa e de projetos de colaboração. Em linhas gerais, suas ações se caracterizam por (Santos; Clinio, 2018).

1) Adoção da Ciência Aberta como política pública em diversos países (Portugal, Holanda e França).

2) Criação de interseções entre Governo Aberto e Ciência Aberta (especialmente nos Estados Unidos, Canadá e, mais recentemente, no Brasil).

3) Impulsão de investimentos em infraestruturas, como a European Open Science Cloud, e de capacitação de recursos humanos através de Programas como o Facilitate Open Science Training for European Research (Foster) (Facilitate..., 20--?), que dispõe de $€ 1$ milhão para"contribuir para uma mudança real e duradoura no comportamento dos pesquisadores europeus, garantindo que Ciência Aberta se torne a norma" ${ }^{\text {. }}$.

4) Necessidade de métricas e indicadores que valorizem práticas de acesso aberto a publicações e dados e recompensem pesquisas que produzam benefícios positivos e tangíveis para a sociedade.

5) Concretude do papel estratégico das agências de fomento e dos financiadores privados através de políticas mandatórias de plano de gestão de dados, além de desenvolver plataformas tecnológicas próprias para publicação aberta de artigos.

6) Necessidade de um sistema de governança que lide com múltiplos interesses e contextos de aplicação. No Reino Unido, por exemplo, vislumbra-se uma instância democrática, responsável e independente capaz de lidar com os interesses de diversos setores e proteger direitos individuais e coletivos.

A partir desse panorama internacional, é possível perceber que o debate sobre a Ciência Aberta vem sendo conduzido majoritariamente por governos nacionais, instituições públicas e agentes financiadores que buscam criar um ecossistema de pesquisa baseado em novas habilidades, práticas, padrões e infraestruturas tecnológicas.

Geralmente, o primeiro argumento mobilizado pelos adeptos da Ciência Aberta é o de promover o avanço da ciência e do conhecimento, através do aprimoramento da comunicação científica, ou seja, a maneira como é tornado comum o conhecimento produzido. Essa motivação é especialmente importante para aqueles que trabalham profissionalmente na atividade de pesquisa na medida que informação e dados são a matéria prima para 4 sua atuação. Por isso, muitas inovações na comunicação científica foram propostas por pesquisadores profissionais. Tais como os preprint de Paul Ginsparg de 1991, os cadernos abertos de laboratório (open notebook science) de Jean-Claude Bradley de 2006, as publicações líquidas de Casati, Giunchiglia e Marchese de 2007, os data papers, entre outros (Clinio; Albagli, 2017).

As críticas sobre o processo atual de comunicação do conhecimento científico vêm sendo absorvidas por editores de revistas científicas que estão implementando mudanças para tornar o sistema de avaliação mais eficiente, além de responder a críticas sobre a qualidade das publicações, a reprodutibilidade e a lentidão do processo de publicação que, em geral, tarda um ano. A Rede SciELO (Scientific Electronic Library Online) está adotando

\footnotetext{
3 "The primary aim is to contribute to a real and lasting shift in the behaviour of European researchers to ensure that Open Science (OS) becomes the norm".
} 
gradativamente as diretrizes Transparency and Openness Promotion (TOP), promovidas pelo Center of Open Science (COS), com objetivo de reforçar e ampliar a transparência, a reprodutibilidade, a visibilidade e a interoperabilidade das pesquisas (Parcker et al., 2018). Essas orientações demandam a explicitação e o referenciamento de fontes de dados, materiais, métodos e códigos de programas de computador utilizados na concepção, realização e comunicação dos projetos de pesquisas e que, na maioria das vezes, encontram-se subjacentes aos artigos. Entre as ações previstas para o seu "alinhamento com as boas práticas de comunicação da Ciência Aberta", o SciELO adotou, em julho de 2018, o formato preprint de publicação de artigos científicos em uma plataforma (em desenvolvimento) que tornará este processo "aberto, transparente e acessível" (Fundação de Amparo à Pesquisa do Estado de São Paulo, 2017).

A adoção do novo formato, consagrado pelo campo da física, é uma das estratégias para garantir o acesso aberto e imediato ao artigo, conferindo maior velocidade na publicação de trabalhos recentes. A expectativa é que a sua adoção ampla fortaleça a função (abalada) das revistas na filtragem, validação e comunicação do conhecimento científico. Se, por um lado, vislumbra-se que "quanto mais transparência houver, maior será a qualidade das publicações" (Fundação de Amparo à Pesquisa do Estado de São Paulo, 2017), alguns editores científicos ponderam que o produtivismo acadêmico, expresso na máxima "publicar ou morrer", continua sendo um grande obstáculo para as necessárias melhorias estruturais. Para Claude Permez, editora da revista Memórias do Instituto Oswaldo Cruz, o formato aumenta a possibilidade de redes colaborativas, mas a comunidade científica deve rever o seu sistema de avaliação (Fundação de Amparo à Pesquisa do Estado de São Paulo, 2017), repensando, por exemplo, o que o "fator de impacto" realmente indica e qual o impacto se deseja obter.

Além de proporcionar o avanço do conhecimento, a questão da reprodutibilidade é outro tema de grande interesse. Apesar de não haver uma definição única para o termo reprodutibilidade, ele se refere à expectativa de que um pesquisador, usando os mesmos métodos descritos por outro cientista, obterá resultados semelhantes. A chamada "crise de reprodutibilidade" é central no debate atual sobre a qualidade em ciência, pois vários estudos recentes indicam uma grande dificuldade ou até a impossibilidade de reproduzir resultados de pesquisa em diversos campos do conhecimento. Em maio de 2016, uma enquete da revista Nature, com cerca de 1,5 mil pesquisadores, revelou que mais de $70 \%$ dos respondentes já tentou, mas não conseguiu reproduzir experimentos de outros pesquisadores. Além disso, mais da metade dos participantes afirmou não ter conseguido reproduzir seus próprios experimentos (Baker, 2016). Segundo os respondentes, as principais causas da baixa reprodutibilidade são a pressão para publicar e o "relato seletivo". Em ambos os casos, a qualidade das comunicações seria prejudicada por descrições inadequadas dos métodos, por dados incompletos ou ainda pela seleção de resultados de pesquisa mais propensos a serem aceitos pelas revistas científicas para publicação.

Na perspectiva da promoção da qualidade em pesquisa, os agentes de fomento também estão investindo na melhoria dos processos e de estruturas. No Brasil, a Iniciativa Brasileira de Reprodutibilidade, do Instituto Serrapilheira, é o primeiro estudo sistemático sobre a reprodutibilidade científica nacional com o objetivo de subsidiar a reflexão sobre práticas individuais e coletivas e "ajudar a colocar o Brasil na vanguarda do desenvolvimento de uma ciência mais confiável a nível mundial" (Iniciativa Brasileira de Reprodutibilidade, 2018).

Melhorar a confiabilidade da pesquisa produzida em um país é um dos argumentos mobilizados por países que adotaram a Ciência Aberta como política nacional. No âmbito europeu, por exemplo, o relatório "Open Science, Open Innovation, Openness to the World: a vision for Europe" (European Comission, 2016) vislumbra que a abordagem aberta torne a "ciência melhor" em três perspectivas: (1) mais confiável e replicável em termos de governança e integridade científica; (2) mais eficiente por evitar a duplicação de recursos; (3) mais aberta por melhorar o acesso a dados e ao conhecimento em todas as etapas do ciclo de pesquisa, viabilizando a mineração de textos e dados em consonância com o direito autoral.

Entre os benefícios para a sociedade, a União Europeia entende que a Ciência Aberta é uma estratégia para fortalecer a excelência científica e o caráter inovador do bloco na medida que a cooperação internacional facilita 
o acesso ao conhecimento novo, aos melhores talentos globais e aos melhores recursos onde quer que estejam localizados. Pretende-se aumentar a competitividade, criar oportunidades para as indústrias de alta tecnologia e acessar mercados emergentes, considerando a importância crescente dos dados na economia global. O relatório europeu também cita o potencial da Ciência Aberta no enfrentamento de problemas sociais complexos, como a mudança climática, a escassez de recursos ou as emergências sanitárias (European Comission, 2016). No entanto, não explicita como isso será posto em prática.

No Brasil, não há uma política de Ciência Aberta, mas registram-se inúmeras iniciativas de instituições públicas de ensino e pesquisa, motivadas pela necessidade de lidar com novas exigências oriundas de agentes de fomento (especialmente os estrangeiros) e revistas científicas. Como exemplo, destaca-se a recente incorporação do tema da Ciência Aberta na Parceria para Governo Aberto (Open Government Partnership), cujo objetivo é "avançar mundialmente no fortalecimento das democracias, na luta contra a corrupção e no fomento a inovações e tecnologias para transformar a governança do século XXI" (Open Government..., 20--?). O 40 Plano de Ação Nacional (2018-2019) comprometeu-se em "estabelecer mecanismos de governança e dados científicos para o avanço da Ciência Aberta no Brasil" (Open Government..., 20--?) e está sendo encampado por instituições como a Fundação Oswaldo Cruz (Fiocruz), a Empresa Brasileira de Pesquisa Agropecuária (Embrapa), o Instituto Brasileiro de Informação em Ciência e Tecnologia (Ibict), a Coordenação de Aperfeiçoamento de Pessoal de Nível Superior (Capes), o Conselho Nacional de Desenvolvimento Científico e Tecnológico (CNPq), a Rede Nacional de Ensino e Pesquisa (RNP), a Universidade de Brasília (UnB) e a Open Knowledge Brasil.

Recentemente, diversos agentes de fomento passaram a exigir a entrega de um Plano de Gestão de Dados (PGD) como pré-requisito para obtenção de financiamento de pesquisa. Instituições privadas de caráter filantrópico e atuação global - como a Bill and Melinda Gates Foundation, a Wellcome Trust e o Open Research Funders Group estabeleceram um caráter mandatório para esse documento, pois reconhecem que "gestão ativa" de dados acelera o ritmo de descobertas, reduz lacunas de informação, incentiva a inovação e promove a reprodutibilidade. No Brasil, onde o fomento à pesquisa é basicamente governamental, a Fapesp passou a exigir, no final de 2017, a apresentação de um plano de gestão de dados em editais temáticos. Essa nova demanda tende a ser incorporada por instituições de ensino superior. Em fevereiro de 2019, a Pró-Reitoria de Pesquisa da Universidade de São Paulo (USP) disponibilizou informações e infraestrutura própria para que os pesquisadores elaborem seus PGD planos e depositem seus dados.

Até aqui, os promotores da Ciência Aberta com incidência no Brasil mobilizam a noção de "abertura" para contrapor, em diferentes graus e combinações, os seguintes obstáculos artificiais que impedem a ampla difusão do conhecimento:

- Econômico: Refere-se aos valores cobrados por editoras comerciais para o acesso ao conteúdo de revistas científicas através de paywalls que corroem orçamentos de bibliotecas e impedem, em última instância, a realização de pesquisas. Há, ainda, mais recentemente, a cobrança de taxas de processamento de artigos que transferem o ônus financeiro do assinante para o autor do artigo.

- Jurídico: O uso abusivo do direito autoral pelas indústrias de editoração científica é considerado prejudicial por criar uma "escassez artificial" de bens intelectuais e dificultar a circulação de informação relevante. Se, por um lado, os direitos autorais protegem a propriedade intelectual por meio de atribuição de exclusividade temporária, por outro lado ele não deve se sobrepor a direitos fundamentais, como educação, acesso à informação e conhecimento, desenvolvimento científico etc. Este difícil equilíbrio é um campo de batalha entre editoras comerciais e dinâmicas sociais que promovem o crescimento exponencial de "cópias não autorizadas", como ocorre na plataforma Sci-hub.

- Técnico: A adoção de formatos abertos é considerada mais adequada para fomentar a circulação da informação, pois favorece a preservação de documentos a longo prazo e a interoperabilidade entre sistemas, além 
de evitar a dependência de indivíduos e instituições de fornecedores que monopolizam um formato. Atualmente, a acumulação de um enorme volume de dados, cuja exploração pode levar à descoberta de padrões e tendências, deu novo impulso ao debate sobre formatos abertos.

- Editorial: Refere-se à intermediação da comunicação do conhecimento por atores que atuam como gatekeepers (editores, autores e avaliadores anônimos) e definem temas prioritários, formatos, critérios de cientificidade e qualidade. Enfim, o que é publicável (ou não) em revistas científicas. As políticas editoriais privilegiam a publicação dos experimentos "bem-sucedidos" em detrimento dos experimentos ditos "fracassados", conflitando com as idiossincrasias de uma atividade que se caracteriza justamente pela "tentativa e erro". Essa opção diminui drasticamente a informação relevante disponível.

\section{Contribuições latino-americanas para o debate sobre a Ciência Aberta}

Os obstáculos listados acima também configuram objeto da atuação de instituições latino-americanas de ensino e pesquisa. No entanto, experiências recentes de Ciência Aberta em outros contextos produziram perspectivas diferentes de abertura que combinam pesquisa e ativismo e promovem novas formas de produção de conhecimento "entre todos" e "para todos". Essas experiências questionam, em diferentes graduações, se a Ciência Aberta é um mecanismo para a manutenção de desigualdades estruturais e dinâmicas de poder ou se ela pode promover justiça cognitiva e justiça social. Nessa perspectiva, o acesso aberto, imediato e completo ao conhecimento científico é considerado uma pré-condição para o estabelecimento de formas coletivas de gestão de bens comuns - sejam eles bens intelectuais, sejam recursos naturais (Ostrom, 1990; Ostrom; Hess, 2007).

\section{A experiência da OCSDNet}

A Open and Collaborative Science in Development Network é uma rede de pesquisa, baseada no Canadá e financiada com recursos do International Development Research Center (IDRC), que promoveu, durante dois anos (2015-2016), 12 projetos de pesquisa para experimentar a Ciência Aberta no chamado Sul Global, incluindo iniciativas na América Latina. Sua proposta era analisar criticamente a Ciência Aberta, a partir de experiências empíricas que pudessem ser contrastadas com o discurso dominante, especialmente aqueles oriundos de instituições públicas. Nesses discursos, há uma tendência de promover uma concepção utilitária da ciência (mais produtiva e eficiente) e relacionar a produção de conhecimento apenas com a inovação e a competitividade internacional, perdendo de vista outras funções igualmente importantes, como atender aos desafios sociais ou auxiliar os cidadãos no acesso a direitos fundamentais (Albornoz, 2018).

Os projetos de pesquisa da OCSDNet formaram parcerias com atores comunitários, que regularmente não são considerados legítimos produtores de conhecimento, para explorar como a Ciência Aberta pode contribuir para sua qualidade de vida. Em conjunto, os participantes foram estimulados a refletir sobre questões como: (1) Participação e representação: Quem participa dos processos de produção do conhecimento? Que vozes são levadas em conta na ciência? (2) Conhecimento: Quem se beneficia da produção de conhecimento? De que maneira a produção de conhecimento reproduz as desigualdades? (3) Tecnologia e acesso: Como podemos usar as ferramentas tecnológicas para aumentar a participação e melhorar os processos de tomada de decisão na produção científica? (Open and Collaborative Science in Development Network, 2017).

Essas questões foram trabalhadas, por exemplo, pelo projeto "Ciência Aberta Ubatuba". Em um primeiro momento, identificou-se que, para além do conhecimento produzido pelas universidades, o município de Ubatuba reúne outros atores cognitivos (indivíduos e organizações) que produzem conhecimento situado justamente pela sua inserção no território. No entanto, como a sua base epistêmica é distinta, suas contribuições são geralmente desconsideradas no debate público. A plataforma LindaGeo, spinoff do projeto, busca reunir as informações 
oriundas das pesquisas e do conhecimento dos atores locais que, na forma de mapas, disputam a definição de políticas públicas sobre o zoneamento ecológico econômico. Nesse sentido, sua noção de abertura estimulou a porosidade entre diferentes matrizes epistemológicas, reconhecendo também diferentes modos de existência e perspectivas sobre a questão do desenvolvimento. Aqui, processos de cocriação visaram aprofundar a própria democracia ao favorecer a participação de mais pessoas em processos decisórios sobre a vida em comum.

Após dois anos de trabalho de campo, tornou-se claro para os participantes da rede que não existe uma única maneira "correta" de fazer Ciência Aberta, pois as inovações devem atender às demandas locais e aos diferentes contextos, exigindo negociação e reflexão constantes. Além disso, o caráter político da Ciência Aberta se tornou evidente. A prática confirmou a produção de efeitos adversos da abertura, especialmente quando: (a) se alinham a discursos meritocráticos que historicamente são utilizados para justificar desigualdades; (b) são mantidos sistemas de privilégio e opressão (colonialismo, capitalismo, patriarcado, supremacia branca) que determinam, no nível estrutural, quem se beneficia e quem se arrisca em um sistema aberto; (c) infringem direitos individuais ou coletivos pela disponibilização de dados pessoais sem consentimento informado e explícito; (d) expõem pessoas a vulnerabilidades e riscos associados à sua participação (Albornoz, 2018).

Na perspectiva da OCSDNet, a abertura não é uma condição binária do objeto que dá suporte ao conhecimento, mas uma questão política que, na perspectiva democrática, deve gerar participação e promover governança coletiva dos bens comuns (Ostrom, 1990). Nesse sentido, Albornoz (2018) destaca o quão importante é refletir constantemente a quem a abertura serve e a quem ela negligencia. A adição do adjetivo "colaborativa"à noção de Ciência Aberta enfatiza a importância da interação entre diversos atores que operam em diferentes contextos institucionais a partir de motivações, valores e intenções distintas (Chan; Okune; Sambuli, 2015). O "Manifesto da Ciência Aberta e Colaborativa: em direção de uma ciência inclusiva pelo bem-estar social e ambiental" (Open and Collaborative Science in Development Network , 2017) propõe sete princípios para torná-la mais inclusiva, os quais são interpretados da seguinte maneira:

1)"Promovero bem comum: A Ciência Aberta deve criar mecanismos e incentivos que permitam aos indivíduos decidirem como usar, compartilhar, governar e gerenciar seu conhecimento para satisfazer as necessidades de desenvolvimento. O conhecimento é um bem comum e deve ser utilizado para a promoção da qualidade de vida da população.

2) Integrar diferentes tradições científicas e formas de saber: A Ciência Aberta deve reconhecer a pluralidade e a diversidade de saberes, e o direito à coexistência, atuando como mecanismo de justiça cognitiva e justiça social.

3) Lidarcom a questão do poder e da desigualdade na produção e distribuição do conhecimento: A Ciência Aberta deve reconhecer efeitos indesejados da abertura e lutar contra as desigualdades estruturais que condicionam a produção e a distribuição de poder. Deve habilitar todos os grupos sociais e expressar claramente as condições de uso e compartilhamento do seu conhecimento.

4) Criar oportunidades para a participação em todas as etapas do processo de pesquisa: A Ciência Aberta deve promover o "direito a pesquisar" de grupos marginalizados em igualdade de condições e capacidade de decisão. Eles aportam mais perspectivas, métodos e cosmovisões ao processo científico.

5) Favorecer a colaboração equitativa entre cientistas e atores sociais: A Ciência Aberta deve promover um espírito de criação conjunta e inovação social, baseado na confiança e apreciação pelos saberes, habilidades e experiências, para promover a colaboração entre pesquisadores profissionais e comunidades.

6) Incentivar o desenho de mecanismos inclusivos de informação e comunicação: A Ciência Aberta deve adotar tecnologias de código aberto, livres, acessíveis e de baixo custo para incluir múltiplos atores com diversas capacidades. 
7) Melhorar o bem-estar da sociedade e do planeta: A Ciência Aberta deve criar capacidades, relações e oportunidades para que as pessoas incidam sobre a agenda de pesquisa, inserindo suas necessidades sociais e ambientais, cocriando soluções sustentáveis, relevantes e inovadoras para desafios complexos.

\section{Declaração do Panamá sobre Ciência Aberta}

Em outubro de 2018, 40 pesquisadores, ativistas e representantes de organizações da sociedade civil, oriundos de quinze países, reuniram-se na Cidade do Panamá para debater, a convite da Fundação Karisma,"o papel da Ciência Aberta para alcançar a educação de qualidade na região". Durante o encontro, foi redigida a primeira versão da "Declaração do Panamá sobre Ciência Aberta", apresentada no Fórum de Ciência para América Latina e Caribe 2018 como um posicionamento regional.

Para subsidiar a sua formulação, os presentes foram divididos em grupos temáticos. O grupo de "localização" abordou a perspectiva latino-americana da Ciência Aberta em quatro rodadas de conversa que buscaram agregar o máximo de visões. Entre as considerações dos participantes, destaca-se o reconhecimento de que a Ciência Aberta é um conceito polissêmico e um movimento que vem sendo liderado por países desenvolvidos, cujos manuais estão sendo adotados por governos latino-americanos sem um debate consistente com a comunidade científica e sociedade.

Suspeita-se que a Ciência Aberta hegemônica pode reproduzir a perspectiva colonial da Ciência Moderna, extraindo riquezas (dados) da América Latina pela capacidade diferenciada dos países desenvolvidos em se apropriar, processar e extrair conhecimento. Resumindo, o temor é que os dados sejam a nova matéria-prima a ser produzida pela América Latina e explorada por terceiros. Por isso, considera-se essencial negociar os termos e condições da sua mais recente fronteira, a abertura de dados, para evitar o agravamento de assimetrias no fazer científico entre países. Outro temor é a salvaguarda de direitos coletivos sobre o conhecimento ancestral frente aos abusos de poder e tentativas de apropriação cultural em campos como sementes, ervas medicinas, moda, tecnologias etc.

Assim como nos países desenvolvidos, a Declaração do Panamá também elenca como estratégias de implantação da Ciência Aberta no continente a formulação de políticas públicas, o estabelecimento de novos indicadores em pesquisa e os investimentos em capacitação e infraestrutura em nível regional. No entanto, o seu diferencial está na ênfase dada ao papel da ciência como "catalisadora de democracia, liberdade e justiça social". Em pelo menos quatro itens, ela expressa claramente o vínculo entre ciência, cidadania e democracia.

\section{Considerações Finais}

Ao contrastar os discursos sobre a Ciência Aberta que estão sendo elaborados e promovidos por governos, instituições de ensino e pesquisa e financiadores com experimentos empíricos, que contaram com a participação de pesquisadores e atores comunitários, percebe-se que há, ao menos, duas perspectivas em disputa do que pode vir a ser a Ciência Aberta na América Latina. Por um lado, mobiliza-se fortemente uma visão utilitarista da ciência, vislumbrando maior eficácia, produtividade e competitividade. Por outro lado, a noção de abertura se orienta para temas como garantia de direitos, justiça cognitiva e justiça social.

Essa dicotomia dialoga estreitamente com a noção de capitalismo acadêmico, elaborada por Slaughter e Leslie (1997), e com a sua descrição de um deslocamento gradativo do valor do conhecimento como bem comum a serviço da cidadania para uma mercadoria a ser comercializada para o benefício de poucos indivíduos e de grandes corporações. Segundo os autores, o capitalismo acadêmico reflete estratégias para compensar a implantação de políticas neoliberais no ensino superior de países desenvolvidos na década de 1980 e os cortes expressivos no 
financiamento público de pesquisa. Ele representa uma importante reorganização da "economia do patrocínio", para usar o termo proposto por David (2008), criando os incentivos para que atores sociais modifiquem o conjunto de instituições, normas, incentivos e estruturas com as quais organizam atividades de ensino e pesquisa. Na prática, adotou-se o discurso do empreendedorismo, além de valores, métricas e profissionais do mundo corporativo, com o objetivo de transformar resultados de pesquisa em mercadorias atraentes em economias pós-industriais, nas quais o conhecimento é um elemento central para a inovação e a competitividade. No regime neoliberal, o bem comum é redefinido em termos de desenvolvimento econômico.

O paradoxo é que as estratégias para garantir a sustentabilidade das universidades se alicerçam na privatização do conhecimento e enfraquecem valores fundamentais da atividade acadêmica, como autonomia e liberdade. Isso ocorre na medida que as instituições se hibridizam com o mercado na tentativa de corresponder às expectativas de clientes e agentes de fomento privados dos quais dependem financeiramente. Dessa forma, a versão contemporânea da Ciência Aberta se insere em um embate mais agudo dos regimes organizacionais característicos da Ciência Moderna: o da disseminação liberal da informação versus a Pesquisa e Desenvolvimento com orientação comercial, na qual os mecanismos de propriedade intelectual são frequentemente utilizados para transformar conhecimento em mercadoria.

Aproximando o debate ao contexto latino-americano, Somers et al. (2018) destacam que o capitalismo acadêmico é um fenômeno estrutural e global, mas que se expressa de maneira diferenciada no continente por conta do reduzido número de parcerias entre universidades e indústrias. Essa característica protegeria, em alguma medida, o papel das universidades como "agente de mudança social", ainda que sejam pressionadas a cumprir metas típicas do capitalismo acadêmico, como aumentar a sua produtividade e a capacidade de inovação e excelência, visando a sua internacionalização e o bom posicionamento em rankings globais.

Como alternativa aos "mandatos do Norte", Somers et al. (2018) citam a antropofagia como prática local capaz de subverter relações de forças pela incorporação e alteração de influências estrangeiras através de um consumo criativo. Faz-se necessária uma apropriação crítica e propositiva do paradigma aberto de modo a proteger a produção do conhecimento científico dos avanços do neoliberalismo. Neylon (2019), um dos primeiros evangelistas da Ciência Aberta, ao estudar a retórica da excelência em pesquisa, agora renovada no argumento da abertura, afirma que ela é parte de uma agenda neocolonial com a pretensão de transferir o controle da produção do conhecimento para agentes alheios à própria comunidade científica e à sociedade em geral. Segundo o autor, a busca de validação externa induz as instituições latino-americanas a adotarem uma "internacionalização" direcionada aos imperativos europeus e norte-americanos e a sistemas de avaliação "objetivos"que, paradoxalmente, são opacos e orientados para o mercado. Somados, esses fatores fomentam comportamentos instrumentais que reforçam a homogeneidade dos participantes da atividade de pesquisa na medida que tais critérios os distanciam das questões relevantes ao seu entorno e de referências locais.

Na contramão dessa tendência, AmeliCA (2019) é uma iniciativa "criada no Sul e para o Sul" com objetivo de promover o acesso aberto à literatura científica a partir do fortalecimento do modelo local de publicação sem fins lucrativos. Seu diferencial é a opção por fortalecer estruturas cooperativas informais, financiadas por instituições públicas, que formam um sistema em que "todos se beneficiam dos investimentos de todos" e preserva a natureza acadêmica e aberta da comunicação científica. Outro exemplo daantropofagia latino-americana é o deslocamento do debate sobre a abertura da ciência como um conjunto de características aplicáveis aos produtos do conhecimento científico - o artigo, o dado - para a desobstrução da colaboração entre várias culturas epistêmicas e matrizes de conhecimento. Essa inversão reaviva as contribuições de uma longa tradição de pensadores e pensadoras, cujas conexões com o entorno reafirmam seu vínculo com as questões locais e podem representar, inclusive, uma vantagem competitiva frente aos pesquisadores de países desenvolvidos na elaboração de soluções para problemas complexos. 


\section{Agradecimentos}

Albornoz, D. Reimagining Open Science Through a Feminist Lens. Open Con. Diversity, Equity and Inclusion, 2018. 1 vídeo (ca. 16 min.) Avaliable from: https://medium.com/@ denalbz/reimagining-open-science-through-a-feminist-lens546f3d10fa65. Cited: 20 Feb. 2019.

AmeliCA. AmeliCA vs plano S: mesmo objetivo, duas estratégias diferentes para alcançar o acesso aberto. 2019. Disponível em: http://www.amelica.org/pt/index. php/2019/01/10/amelica-vs-plan-s-mismo-objetivo-dosestrategias-distintas-para-lograr-el-acceso-abierto. Acesso em: 7 set. 2019.

Baker, M. Is there a reproducibility crisis? Nature, v.533, p.452-454, 2016. Avaliable from: https://www.nature.com/polopoly fs/1.19970!/menu/main/topColumns/topLeftColumn/pdf/5 $\overline{3}$ 3452a.pdf. Cited: 17 Jul. 2018.

Chan, L.; Okune, A.; Sambuli, I. In: Albagli, S.; Maciel, M.L.; Abvdo, A. (Org). Ciência aberta, questões abertas. Brasília: IBICT, 2015. 312p. Disponível em: http:/livroaberto.ibict.br/ handle/1/1060. Acesso em: 12 set. 2016.

Clinio, A.; Albagli, S. Cadernos abertos de laboratório e publicações líquidas: novas tecnologias literárias para uma Ciência Aberta. Revista Eletrônica de Comunicação, Informação e Inovação em Saúde, v.11, p.1-17, 2017. Suplemento. Disponível em: https://www.reciis.icict.fiocruz.br/index.php/reciis/ article/download/1427/pdf1427. Acesso em: 20 dez. 2017.

David, A. P. The Historical Origins of 'Open Science': An Essay on Patronage, Reputation and Common Agency Contracting in the Scientific Revolution. Capitalism and Society, v.3, n.2, Article5, 2008. Available at: https://ssrn.com/ abstract=2209188. Cited: 23 Jan. 2019.

Declaración de Panamá sobre Ciencia Abierta. Disponible en: https://gitlab.com/declaracion depanama/declaracionde-panama/commit/2a6cb1120832bd5ce255242227e47 da529912717. Acceso en: 23 Enero 2019.

European Comission. Open Science, open Innovation, openness to the World: A vision for Europe. 2016. Available from: http://ec.europa.eu/newsroom/dae/document.cfm?doc_ $i d=16022$. Cited: 20 Sept. 2018.

Facilitate Open ScienceTraining for European Research (Foster). About. Available from: https://www.fosteropenscience.eu/ about. Acesso em: Cited: 16 Sept. 2018.

Fundação de Amparo à Pesquisa do Estado de São Paulo. SciELO anuncia adoção de preprint em 2018. São Paulo: SciELO, 2017. Disponível em: http:/agencia.fapesp.br/scieloanuncia-adocao-de-ipreprint-i-em-2018/26896. Acesso em: 1 ago. 2018.

Iniciativa Brasileira de Reprodutibilidade. O que é a iniciativa? Disponível em: https://www.reprodutibilidade.bio.br. Acesso em: 15 set. 2018.
Mirowski, P. The future(s) of open science. Social Studies of Science, v.48, n.2, p.171-203, 2018. Doi: http://dx.doi. org/10.1177/0306312718772086

Neylon, C. Research excellence is a neo-colonial agenda (and what might be done about it). In: Kraemer-Mbula, E. et al. (Ed.). Transforming Research Excellence. Cape Town: African Minds, 2019. In press. Doi: http://dx.doi.org/10.17613/bta3-6g96

Open and Collaborative Science in Development Network. Manifiesto de Ciencia Abierta y colaborativa. Hacia una ciencia abierta inclusiva por el bienestar social y ambiental. 2017. Disponíble en: https://ocsdnet.org/wp-content/ uploads/2015/04/Manifesto-Infographic-Spanish-1.pdf. Acceso en: 1 fev. 12018.

Open Government Partnership. O 4 Plano de Ação Nacional (2018-2019). Disponível em: https://governoaberto.cgu.gov. br/a-ogp/planos-de-acao/4o-plano-de-acao-brasileiro/4oplano-de-acao-nacional_portugues.pdf. Acesso em: 16 set. 2019.

Open Knowledge International. Open Science Working Group, [200--?]. Available from: http://science.okfn.org/\#sthash. ZOMzf8 Fg.dpuf. Cited: 3 Nov. 2013.

Ostrom, E. Governing the commons: The evolution of institutions for collective action. Cambridge: Cambridge University Press, 1990.

Ostrom, E.; Hess, C. Understanding Knowledge as a Commons: From Theory to Practice. London: MIT Press, 2007.

Parcker, A.L. et al. Os critérios de indexação do SciELO alinham-se com a comunicação na ciência aberta. SciELO em Perspectiva, 2018. Disponível em: https://blog.scielo. org/blog/2018/01/10/os-criterios-de-indexacao-do-scieloalinham-se-com-a-comunicacao-na-ciencia-aberta/. Acesso em: 20 set. 2019.

Posada, A.; Chen, G. Inequality in knowledge production: The integration of academic infrastructure by big publishers. Toronto:ELPUB,2018.Doi:http://dx.doi.org/10.4000/proceedings. elpub.2018.30.

Santos, P.X. (Coord.). Livro Verde, ciência aberta e dados abertos: mapeamento e análise de políticas, infraestruturas e estratégias em perspectiva nacional e internacional. Rio de Janeiro: Fiocruz, 2017. Disponível em: https://www.arca. fiocruz.br/handle/icict/24117. Acesso em: 15 set. 2018.

Santos, P.X.; Clinio, A. Sumário Executivo Livro Verde: Ciência aberta e dados abertos: mapeamento e análise de políticas, infraestruturas e estratégias em perspectiva nacional e internacional. Rio de Janeiro: Fiocruz, 2018. Disponível em: https://www.arca.fiocruz.br/handle/icict/26809. Acesso em: 30 jun. 2018. 
Slaughter S, Leslie L. Academic Capitalism: Politics, Policies and the Entrepreneurial University. Boston: Johns Hopkins UP, 1997.

Somers P. et al. Academic capitalism and the entrepreneurial university: some perspectives from the Americas. Roteiro, v.43, n.1, p.21-42, 2018. Available from: https://www.researchgate. net/publication/324458855_Academic_capitalism_and_ the_entrepreneurial_university_some_perspectives_from_ the_Americas. Cited: 21 Sept. 2019.

Souza, H.J. Como se faz análise de conjuntura. 27.ed. Petrópolis: Editora Vozes, 1984.

Waters, A. From "Open" to Justice: Audrey Watters @ OpenCon 2014. Available from: https://www.youtube.com/watch?v= mZiiLVPvsT8. Cited: 1 Jan. 2016. 